\title{
Fault Diagnosis in a Permanent Magnet Synchronous Generator based Variable Speed Grid-connected Wind Power Conversion
}

\author{
Kyeong-Hwa Kim \\ Department of Electrical and Information Engineering \\ Seoul National University of Science and Technology \\ 232 Gongneung-ro, Nowon-gu, Seoul, 139-743, Korea \\ k2h1@seoultech.ac.kr
}

\begin{abstract}
Switch open fault characteristics and simple diagnosis scheme in a permanent magnet synchronous generator (PMSG) based variable-speed grid-connected wind power conversion are presented. In the back-to-back converter, the failure in switching devices may occur either in a machine side converter (MSC) or in a grid side converter (GSC), which decreases the generator output power and degrades the stability in wind power generation system. To detect such a fault, a monitoring scheme for the second-order harmonic components in the $q$ axis current is proposed, where the harmonic values are simultaneously observed in the MSC as well as in the GSC to monitor abnormal operation of system. To determine the harmonic values irrespective of operating conditions, the normalized currents are employed for the harmonic calculation. To verify the effectiveness of the proposed fault diagnosis scheme, the comparative simulation results are presented. As a result, an on-line simple diagnosis scheme which monitors the condition of generation system can be realized without requiring any additional hardware equipment.
\end{abstract}

Keywords: Diagnosis, Harmonic components, PMSG, Switch open fault, Wind power

\section{Introduction}

Among various renewable energy resources connected to the grid, wind power generation is recognized as the most competitive and economic one, which leads to a rapid growth in the global wind power generation capacity [1-2]. A permanent magnet synchronous generator (PMSG) using a back-to-back converter for a variable-speed wind power generation has the advantages of simple structure, high efficiency, wide operating range, and no loss in field winding. Moreover, the permanent magnet excitation allows generators to have a smaller pole pitch as compared with the conventional ones, which makes it possible to design a generator at rated speeds of 20-200 rpm by adopting multiple pole configurations [3].

In a variable-speed PMSG based wind power generation system, a back-to-back converter is generally located between the generator and grid to convert the generator output power in variable voltage and frequency to the fixed voltage and frequency of grid [4]. The back-toback converter consists of two power electronics converters. One is the machine side converter (MSC) to convert the generated AC power into DC power and the other is the grid side converter (GSC) to convert the DC power into AC power in grid frequency. Whereas the MSC controls the generator speed to draw the maximum output power from wind turbine, the GSC controls the frequency and active/reactive powers for grid connection.

As the level of wind energy penetration in the electrical power system is increased, the issue of improving the reliability and stability in the utility grid as well as wind power 
generation system has become a major concern. This issue will become much more important considering that the recent large-scale wind power systems are often built in off shore or remote locations. An advanced maintenance scheme through a condition monitoring based on sensor network has been reported for the wind power system [5]. The analysis on the average fault rate in a wind power generation system has been presented in detail [6]. According to this work, the bearing, generator, rotor eccentricity, and electrical components are the main cause of faults. Among the faults in electrical components, $50 \%$ of the faults occur in the power converter such as back-to-back converters, and the other $50 \%$ in the remaining components. As a fault-tolerant operation, a modular power electronic converter has been proposed using isolated generator coils [7]. Although some fault detecting schemes of inverter as single unit have been studied [8], those under the direct connection to the wind turbine are not sufficient.

A literature review on the fault diagnosis and protection methods of IGBT has been presented for power inverters [9]. Performance investigation and observer-based condition monitoring scheme have been studied for a PMSG based grid-connected wind power system under switch open fault [2]. A diagnosis method for the IGBT open switch fault has been developed for three-phase AC/DC PWM converter [10]. A voltage based approach to detect the open-switch fault without additional hardware has been proposed in the closed-loop PWM $\mathrm{AC}$ drives [11]. In this scheme, the information contained in the reference voltages which are available from the controller has been used as detection variables. Four detection techniques have been introduced for fault detection in voltage-fed PWM motor drive systems [12].

In the early stage of fault, the entire system may still operate. If left undetected, however, such a fault may easily bring about another failure. Even a minor fault can be rapidly expanded to many portions of system since the wind turbines often have severe mechanical and environmental stresses. Thus, to minimize the loss by detecting the fault at the initial stage, on-line basis fault diagnosis schemes are much required for the wind power system, where the controller should detect a fault during operation without any additional diagnostic equipment.

There are several reasons that cause an open-switch fault. Thermal cycling may cause lifting of bonding wires and this in turn makes an open-switch fault occur. High collector current is also another cause of an open-switch fault. Finally, the failure in gate driver circuits is one of the most common causes of open-switch fault. If any kinds of open-switch faults occur either in a MSC or in a GSC, the power supplied to the grid is reduced continuously. Even if there are some passive protection devices such as the fuses or circuit breakers, such a protection disconnects the power sources and the continuous operation will be stopped suddenly.

In this paper, switch open fault characteristics and simple diagnosis scheme in a back-toback converter are presented for a PMSG-based variable-speed grid-connected wind power conversion. In the back-to-back converter, the failure in switching devices may occur either in the MSC or in the GSC, which decreases the generator output power and degrades the stability in wind power generation system. Switch open faults are mainly due to the damage caused by over-current and prevent the normal operation of system. To detect such faults, a monitoring scheme for the second-order harmonic components in the $q$-axis current is proposed, where the harmonic values are simultaneously observed in the MSC as well as in the GSC to monitor abnormal operation. To determine the harmonic values irrespective of operating conditions, the normalized currents are employed for the harmonic analysis. The comparative simulation results are presented to verify that the proposed scheme is effective to detect the switch open fault in the back-to-back converter. As a result, an on-line simple 
diagnosis scheme which monitors the condition of generation system can be realized without requiring any additional hardware equipment.

\section{Back-to-back Converter in Grid-connected Wind Power Systems}

The overall configuration of a wind power generation system employing a back-to-back converter is shown in Figure 1. The kinetic energy of wind produces a mechanical torque by a wind turbine, which is converted into the electric energy through the PMSG and back-to-back converter to supply to grid. The power converted by a wind turbine is expressed as follows [13]:

$$
P_{b}=0.5 A \rho V_{\text {wind }}^{3} C_{p}(\lambda, \beta)
$$

where $A$ is the cross sectional area of the rotor blade $\left[\mathrm{m}^{2}\right], \rho$ is the air density $\left[\mathrm{kg} / \mathrm{m}^{3}\right], V_{\text {wind }}$ is the wind velocity $[\mathrm{m} / \mathrm{s}], C_{p}$ is the power coefficient of the turbine, $\beta$ is the pitch angle, and $\lambda$ is the tip speed ratio (TSR). The power coefficient $C_{p}$ is usually given as a function of the $\lambda$ as well as $\beta$. The power coefficient $C_{p}$ represents the power conversion efficiency of the wind turbine and is expressed as [13]

$$
C_{p}=c_{1} \cdot\left(c_{2}-c_{3} \beta-c_{4} \beta^{x}-c_{5}\right) \cdot e^{-c_{6}} .
$$

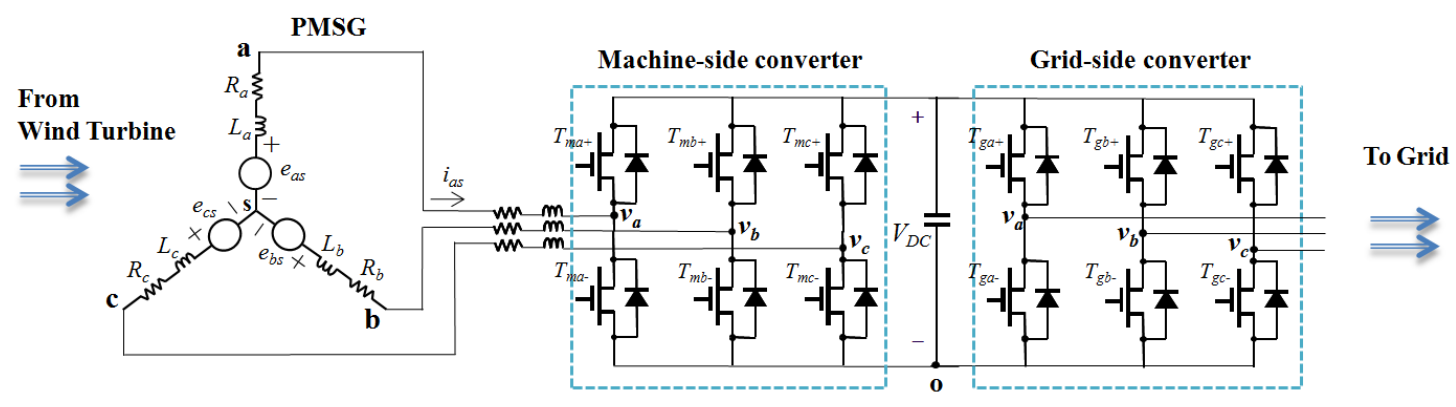

Figure 1. Configuration of a Wind Power System Employing Back-to-back Converter

Figure 2 shows the configuration of a controller for a wind power system. The speed and torque controls of the PMSG are achieved by a current control of the MSC. The current control is accomplished on the synchronous reference frame using the $q$-axis current reference of $i_{q e m}^{*}=T_{b \max } / K_{t}$ and the $d$-axis current reference of $i_{d e m}^{*}=0$ for unity power factor. With the PI decoupling control, the voltage references are calculated as follows:

$$
\begin{gathered}
v_{q e m}^{*}=-\left(k_{p m}+k_{i m} / s\right)\left(i_{q e m}^{*}-i_{q e m}\right)-\omega_{r} L_{d} i_{d e m}+e_{q e m} \\
v_{d e m}^{*}=-\left(k_{p m}+k_{i m} / s\right)\left(i_{d e m}^{*}-i_{d e m}\right)+\omega_{r} L_{q} i_{q e m}
\end{gathered}
$$

where the subscript " $\mathrm{m}$ " denotes the variables in the MSC, the symbol "*" denotes the reference quantity, $v_{q e m}$ and $v_{d e m}$ are the $q$-axis and $d$-axis stator voltages, respectively, $i_{q e m}$ and $i_{d e m}$ are the $q$-axis and $d$-axis stator currents, respectively, $L_{q}$ and $L_{d}$ are the $q$-axis and $d$ axis inductances, respectively, $\omega_{r}$ is the electrical angular velocity of the generator, $s$ is the Laplace operator, and $k_{p m}$ and $k_{i m}$ represent the PI gains, respectively. Using the voltage references in (3) and (4), the transfer function from $i_{q e m}^{*}$ to $i_{q e m}$ can be obtained as follows: 


$$
T(s)=\frac{I_{q e m}(s)}{I_{q e m}^{*}(s)}=\frac{k_{p m} s+k_{i m}}{L_{q} s^{2}+\left(R_{s}+k_{p m}\right) s+k_{i m}} .
$$

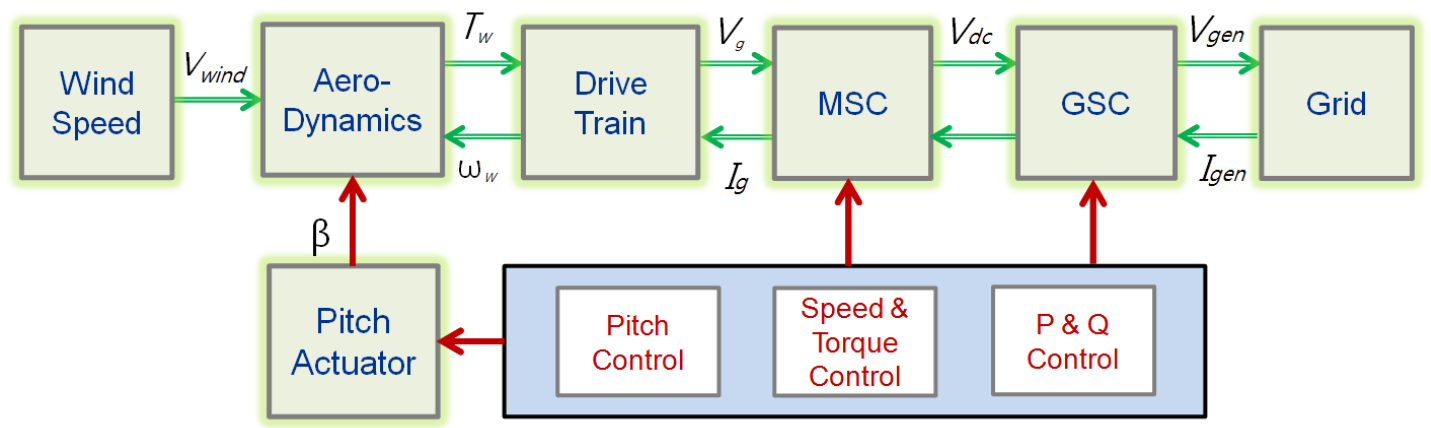

Figure 2. Configuration of a Controller for a Wind Power System

From the second-order transfer function in (5), the current controller bandwidth $\omega_{B}$ can be effectively determined using the damping ratio and natural frequency [14]. Also, the transfer function and bandwidth for the $d$-axis current can be determined in a similar way. In the MSC, the $q$-axis and $d$-axis components of the currents control the generator torque and power factor, respectively, and the computed voltage references are applied with the space vector PWM technique [15].

In a variable-speed wind power system employing a back-to-back converter, while the MSC controls the generator torque and power factor through the current control, the GSC delivers the generated power to grid by controlling the inverter output current in phase with the grid voltage. When the input power to DC link becomes larger than the output power to grid, the DC link voltage is increased, and in the opposite case, the DC link voltage is decreased. By controlling the DC link voltage at constant level, the GSC can deliver the generated power from the MSC to grid. Using the PI control, the voltage controller can be obtained as

$$
i_{q e g}^{*}=-\left(k_{p v}+k_{i v} / s\right)\left(V_{D C}^{*}-V_{D C}\right)
$$

where the subscript "g" represents the variables in the GSC and $V_{D C}$ is the DC link voltage. Using (6) and $i_{d e g}^{*}=0$, the current controller is achieved using the PI decoupling control on the synchronous reference frame as follows:

$$
\begin{aligned}
& v_{q e g}^{*}=\left(k_{p g}+k_{i g} / s\right)\left(i_{q e g}^{*}-i_{q e g}\right)+\omega_{e} L_{s} i_{d e g}+e_{q e g} \\
& v_{d e g}^{*}=\left(k_{p g}+k_{i g} / s\right)\left(i_{d e g}^{*}-i_{d e g}\right)-\omega_{e} L_{s} i_{q e g}+e_{\text {deg }}
\end{aligned}
$$

where $e_{q e g}$ and $e_{d e g}$ are the $q$-axis and $d$-axis grid voltages, respectively, and $i_{q e g}$ and $i_{d e g}$ are the $q$-axis and $d$-axis GSC currents, respectively, $k_{p g}$ and $k_{i g}$ represent the PI gains in the GSC, respectively.

\section{Open Fault Characteristics and Diagnosis Scheme}

When the switch open fault occurs in the MSC or GSC in a back-to-back converter, it will not be able to control the TSR in order to maintain the power coefficient of turbine at maximum. As a result, the maximum generated power as well as proper power conversion cannot be obtained in wind power system. Thus, an exact fault diagnosis is demanded to 
improve the reliability and efficiency of system. When an open fault occurs in switching devices, three-phase balanced condition does not hold. The conventional $d q$ variables in the MSC or GSC are not in pure DC components and include some second-order harmonic terms.

In this section, open faults are detected in real time by monitoring the second-order harmonic components in the $q$-axis current. Figure 3 shows the process to calculate the second-order harmonic components in the MSC or GSC. To calculate the second-order harmonics in the $q$-axis current, the system should be in the steady-state since the harmonic analysis can be accomplished only in steady-state. The steady-state condition can be determined using the angular speed information of the generator and grid voltages. Once the steady-state condition is satisfied, the fundamental frequency and the number of periodic data are determined for harmonic analysis. To obtain the second-order harmonic components irrespective of operating speed and current level, the $q$-axis currents in the MSC and GSC are normalized using the magnitude of current vector as

$$
\begin{aligned}
& i_{q n, m}=i_{q e m} /\left|\boldsymbol{i}_{s, m}\right| \\
& i_{q n, g}=i_{q e g} /\left|\boldsymbol{i}_{s, g}\right|
\end{aligned}
$$

where $\left|\boldsymbol{i}_{s, m}\right|=\sqrt{i_{q e m}^{2}+i_{d e m}^{2}}$ and $\left|\boldsymbol{i}_{s, g}\right|=\sqrt{i_{q e g}^{2}+i_{d e g}^{2}}$. Using these normalized currents $i_{q n, m}$ and $i_{q n, g}$, the harmonic analysis is carried out. This procedure is done simultaneously in the MSC as well as in the GSC to determine the second-order harmonic components $h_{q 2, M S C}$ and $h_{q 2, G S C}$ in the MSC and in the GSC, respectively. By monitoring the second-order harmonic terms in the $q$-axis current, the switch open fault in the back-to-back converter can be effectively detected.

\section{Simulation Result}

To verify that the proposed scheme is effective to detect the switch open fault, the simulation results are presented. The simulation has been done by using the PSIM software and the main controller is implemented with DLL blocks. The overall system consists of a wind turbine, a PMSG, a MSC, a GSC, and DLL blocks for the control and diagnosis algorithms. The sampling period is selected as $100 \mu \mathrm{sec}$ for a current control in the MSC and GSC, and the computed reference voltages are applied through the symmetrical space vector PWM technique. Figure 4 shows the PSIM structure to develop a switch open fault in backto-back converter.

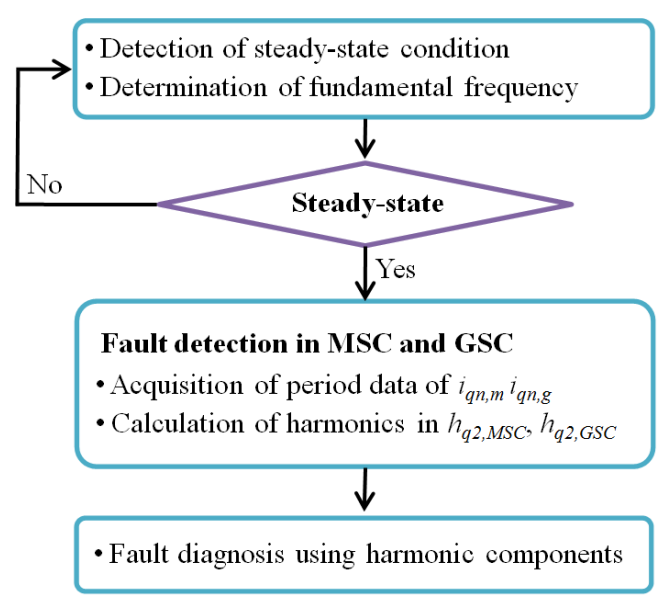

Figure 3. Process for Calculating the Second-order Harmonic Components 


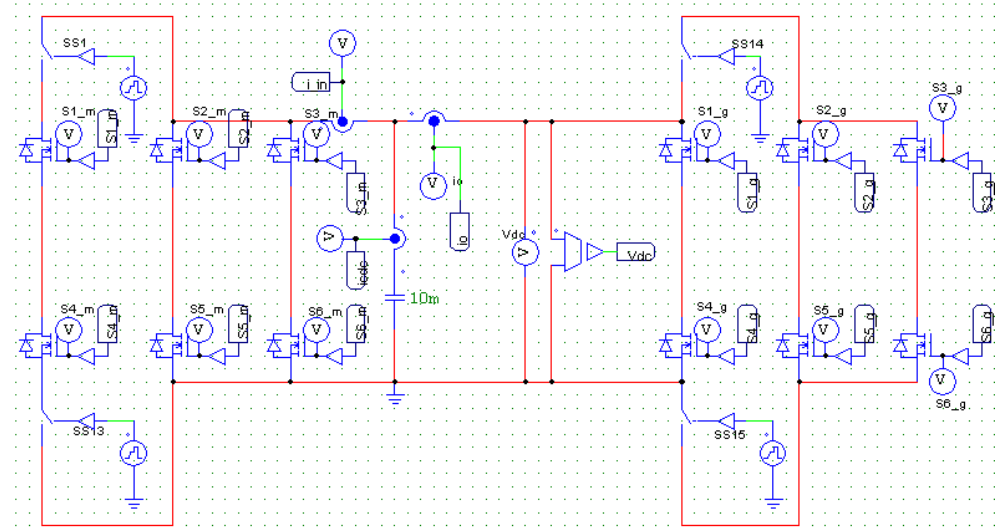

\section{Figure 4. PSIM Configuration to Develop a Switch Open Fault in Back-to-back Converter}

Figure 5 shows the simulation results for the wind power generation system under the normal operating conditions. While the MSC starts operation at $t=0$, the GSC does at 0.05 sec. The first figure shows $a$-phase voltage $v_{a s m}$ and current $i_{a s m}$ in the MSC. The phase current is sinusoidal and in phase with voltage, providing unity power factor. The second figure represents $a$-phase grid voltage $e_{a s g}$ and current $i_{\text {asg }}$ controlled by the GSC. The GSC output current is also sinusoidal and in phase with the grid voltage, which delivers the power to grid with unity power factor. The third figure shows the control performance of the DC link voltage and the last figure shows the current control performance.
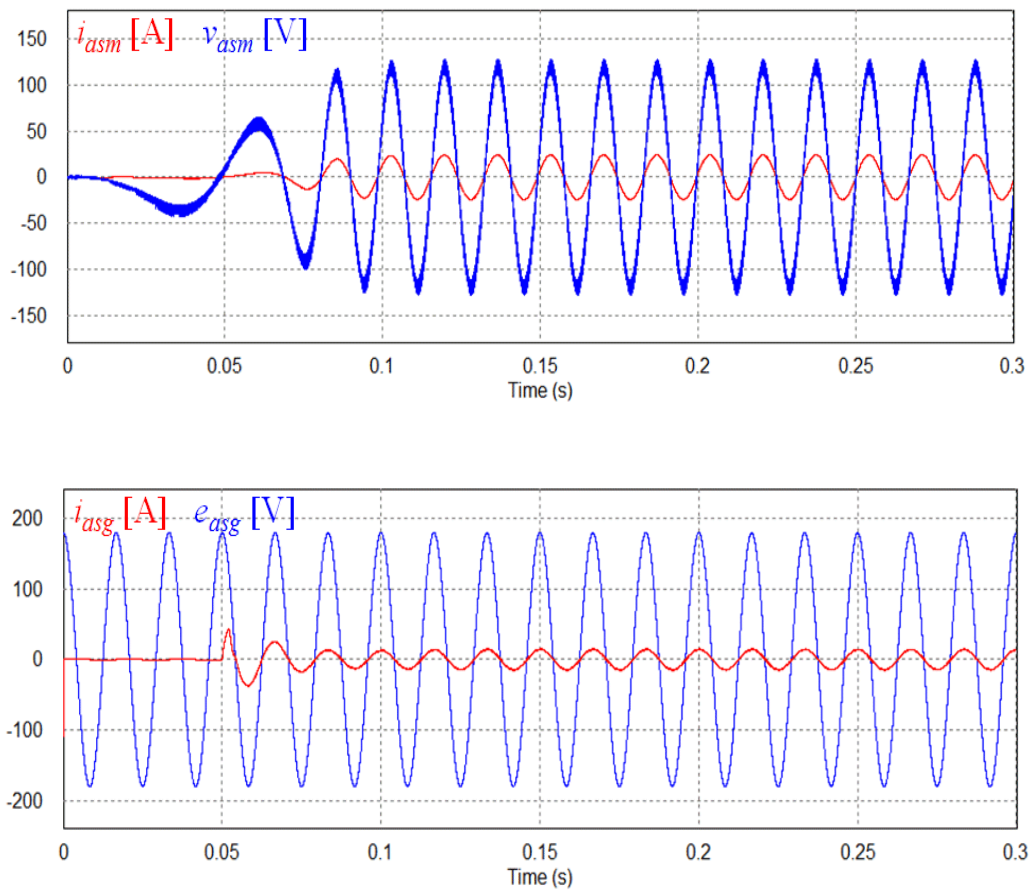

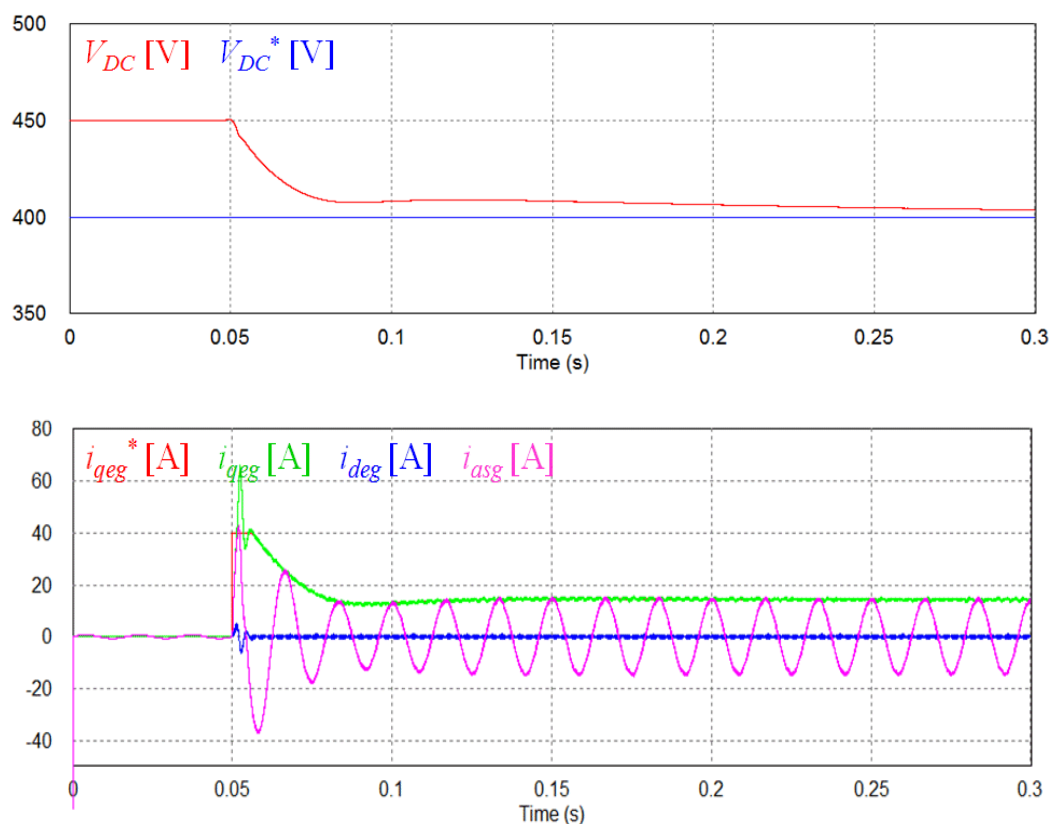

Figure 5. Simulation Results under the Normal Operating Conditions

Figure 6 shows the simulation results for the fault detection when $T_{m a+}$ in the MSC has an open fault at $0.2 \mathrm{sec}$. Due to the open fault, the system operation is changed abnormally from $0.2 \mathrm{sec}$. Since three-phase currents cannot maintain balanced condition, the second-order harmonics are developed in the $q$-axis current. Also, the generator voltage waveform as well as the control quality in the DC link voltage is deteriorated. This disturbs a proper power conversion from the wind turbine to grid, resulting in the decrease in power factor and grid output power. The harmonic calculation for the open fault detection starts at $0.13 \mathrm{sec}$. Whereas the second-order harmonic values $h_{q 2, M S C}$ and $h_{q 2, G S C}$ in the MSC and GSC remain nearly zero under the normal conditions, the value of $h_{q 2, M S C}$ in this case is increased considerably, which indicates an occurrence of open fault in the MSC.

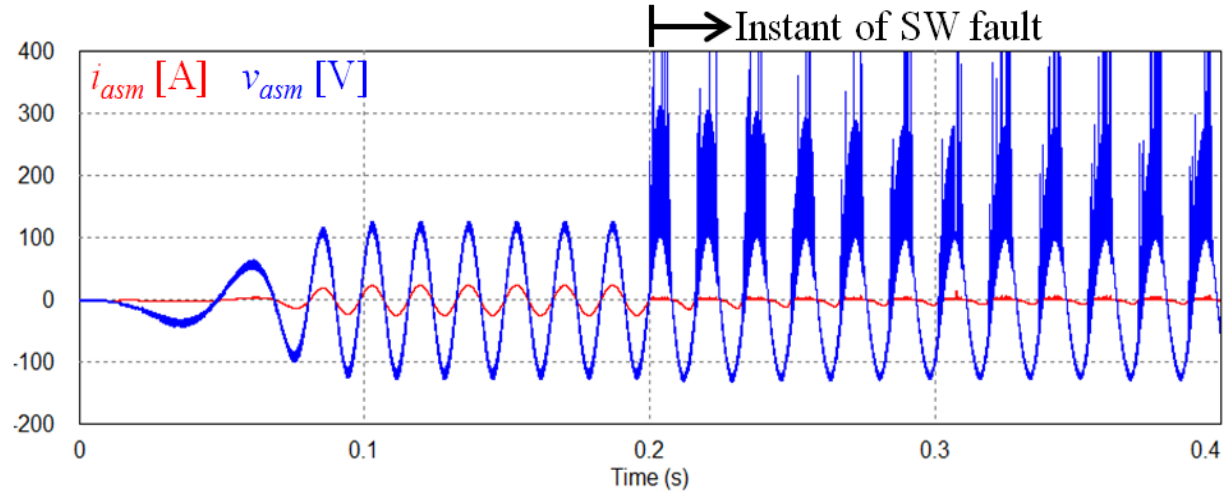



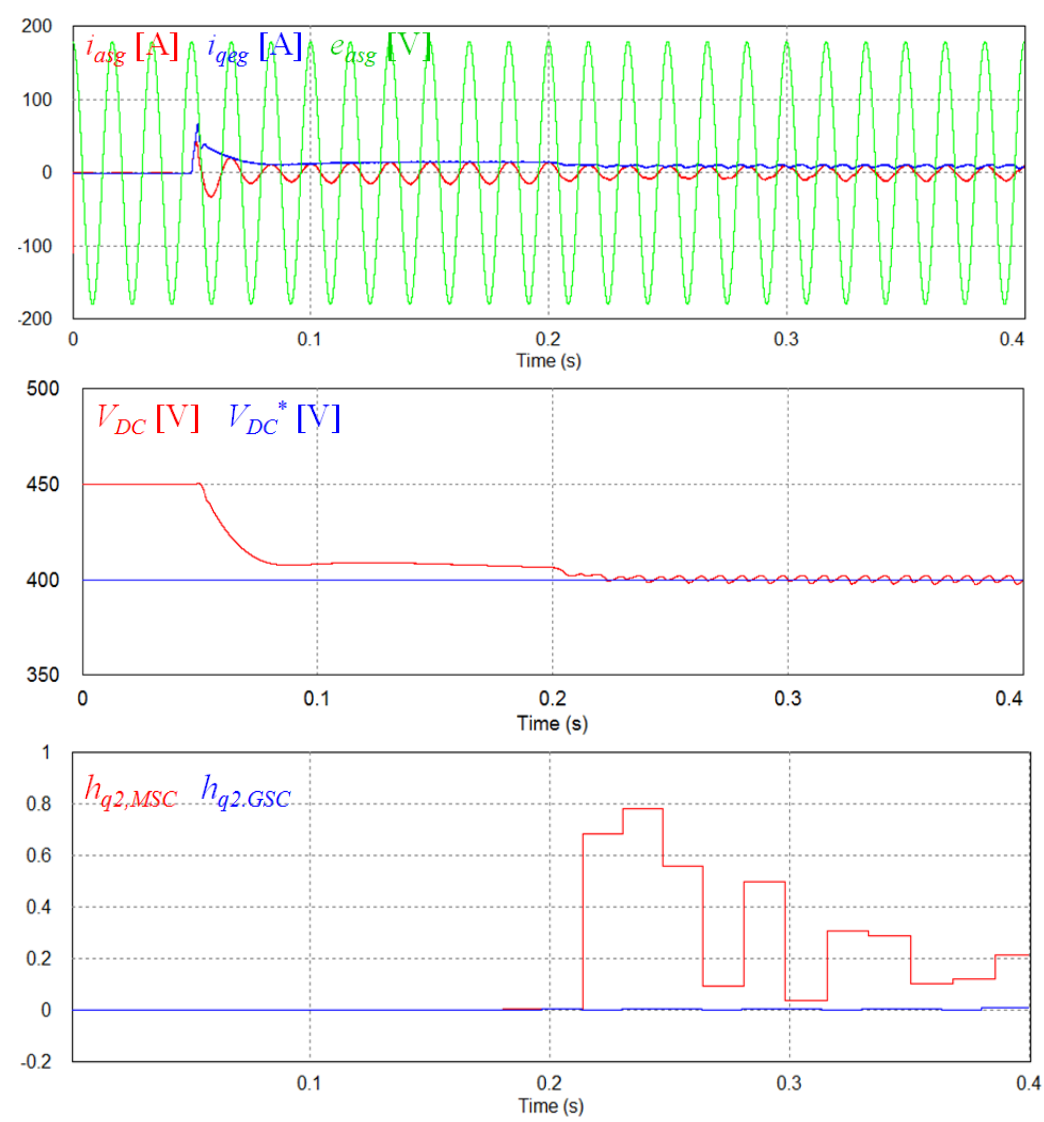

Figure 6. Simulation Results under $\boldsymbol{T}_{\mathrm{ma}+}$ Open Fault in the MSC

Figure 7 illustrates the simulation results when the entire $a$-phase switch in the MSC has open fault. When the open fault occurs in the switches in entire leg, $a$-phase cannot be supplied from the generator. The $a$-phase current is maintained to zero and the other two phases have currents with opposite sign. A proper power conversion cannot be achieved and the severe performance degradation is produced in this case. The proposed scheme can be effectively used to detect the switch open fault even in this case.

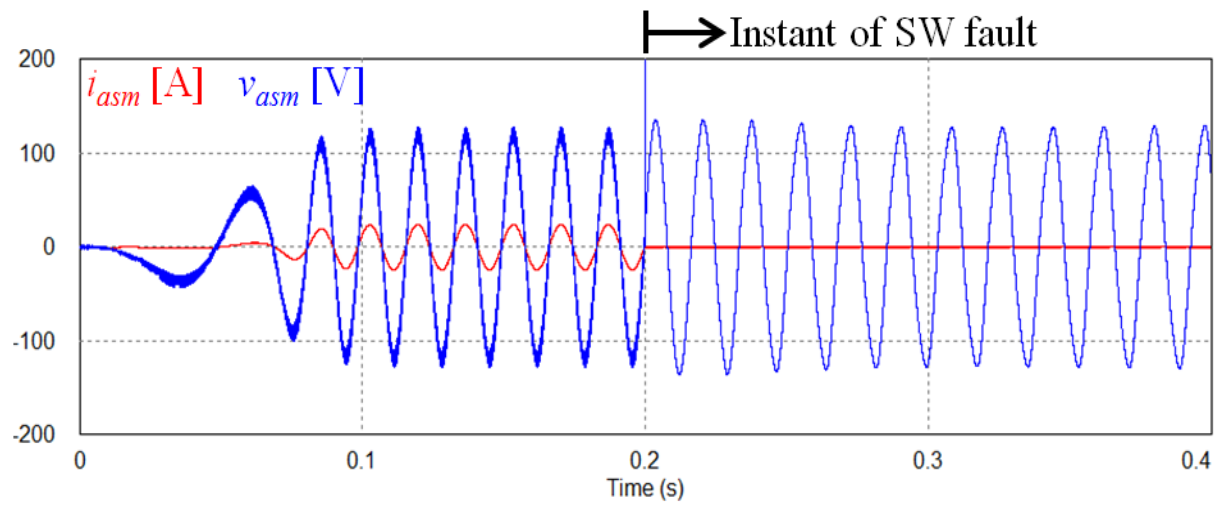



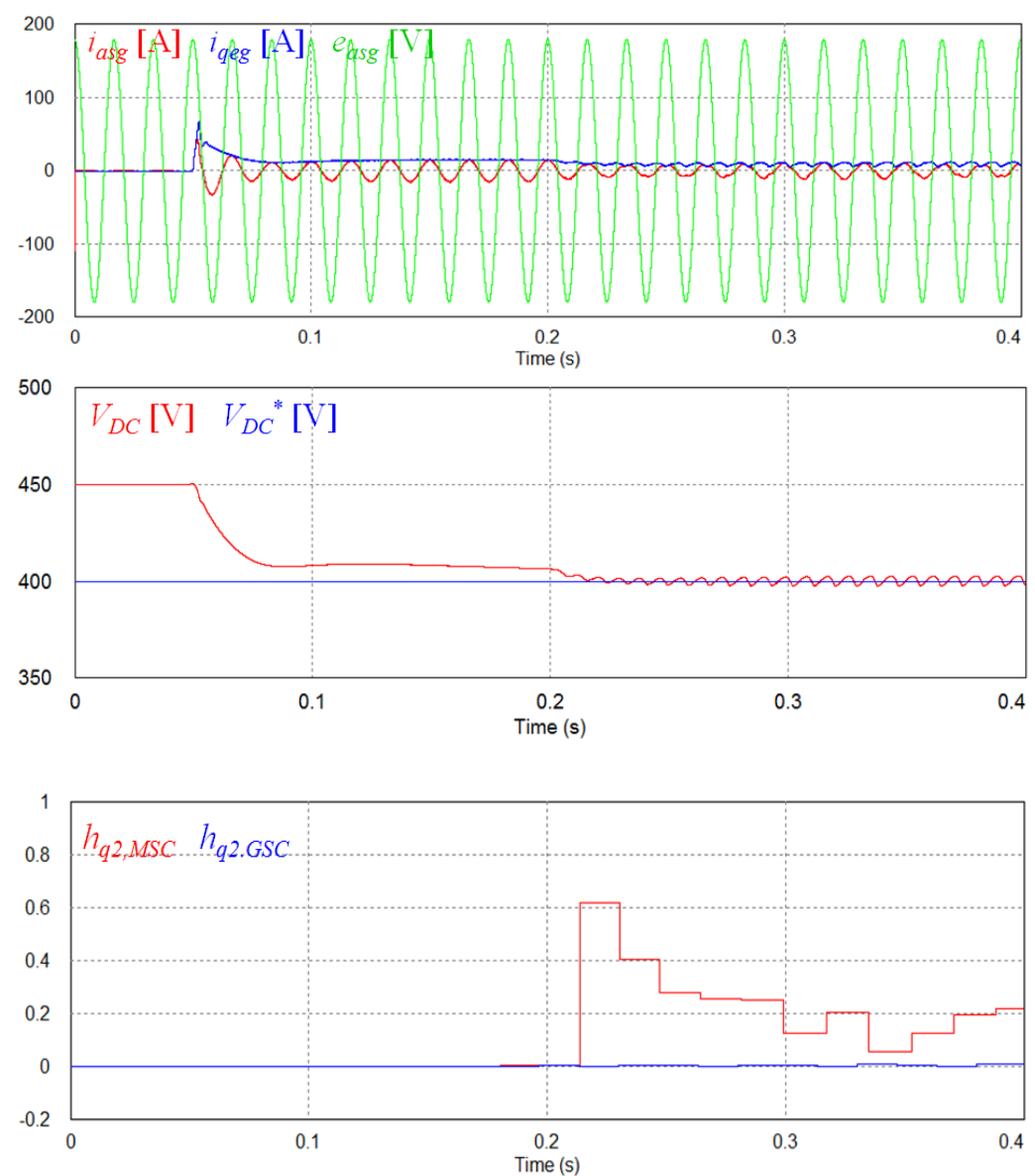

Figure 7. Simulation Results under Entire Switch ( $T_{m a+}$ and $\left.T_{m a-}\right)$ Open in the MSC

Figure 8 and Figure 9 show the simulation results when the GSC has open fault at $T_{g a+}$ and at switches in the entire leg, respectively. In these cases, the second-order harmonic component $h_{q 2, G S C}$ is significantly increased instead of the values $h_{q 2, M S C}$, which means that the GSC is operated in abnormal state while the MSC is in normal operating condition. It is noted that these cases may yield a catastrophic situation unless the whole system does not stop promptly. As is well observed in the third figure, the DC link voltage is dramatically increased when the GSC cannot work properly. Even though the power is continuously injected into the DC link from the wind turbine due to the normal operation of the MSC, this power cannot be effectively transferred to grid due to the failure in the GSC. This injected power continuously increases the DC link voltage to destroy the DC link capacitor.

From these results, it can be confirmed that monitoring the second-order harmonic in the $q$ axis current can be used effectively to detect an abnormal operation in the back-to-back converter. 
International Journal of Control and Automation Vol.8, No.3 (2015)
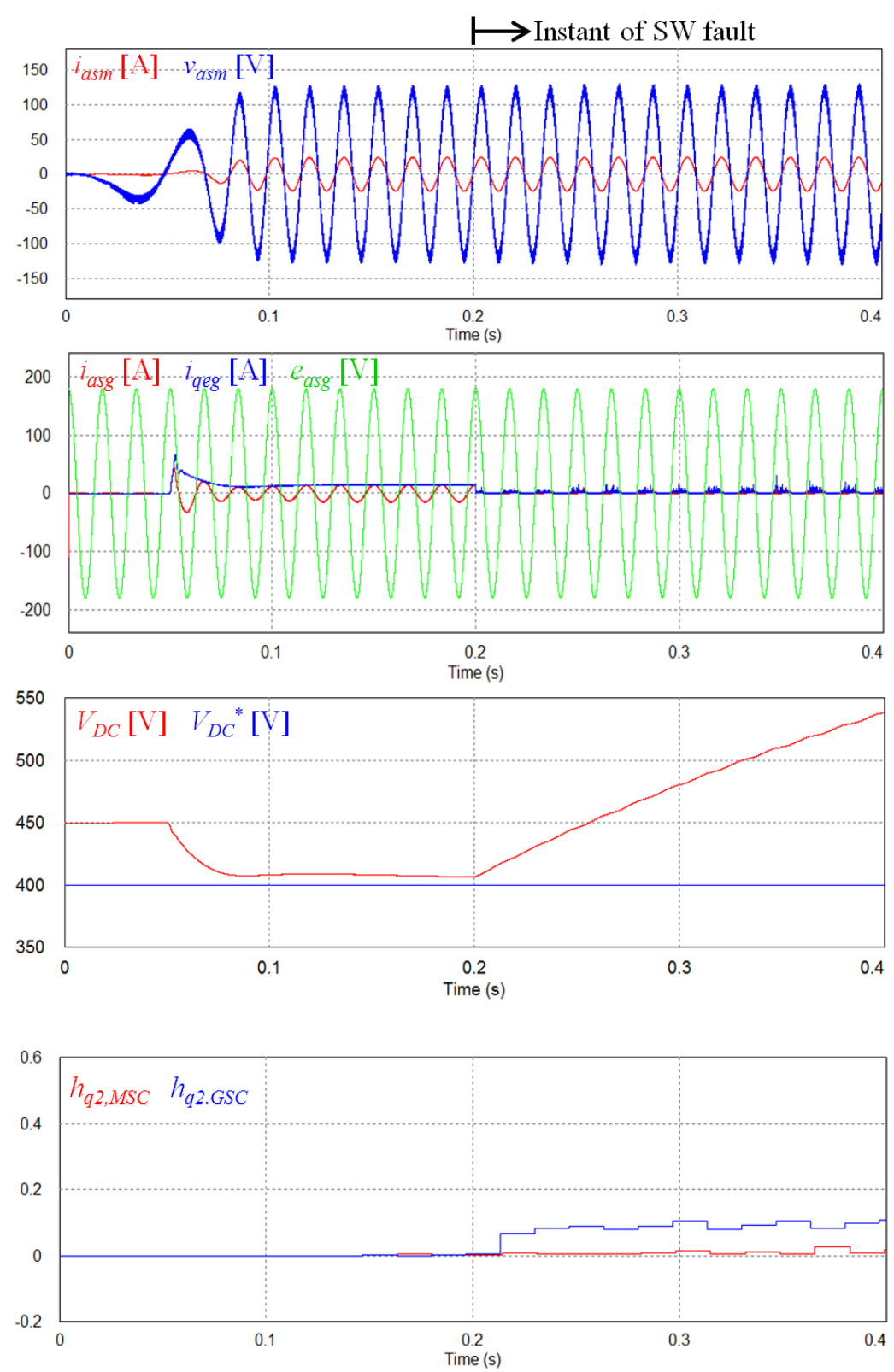

Figure 8. Simulation Results under $T_{g a+}$ Open Fault in the GSC 

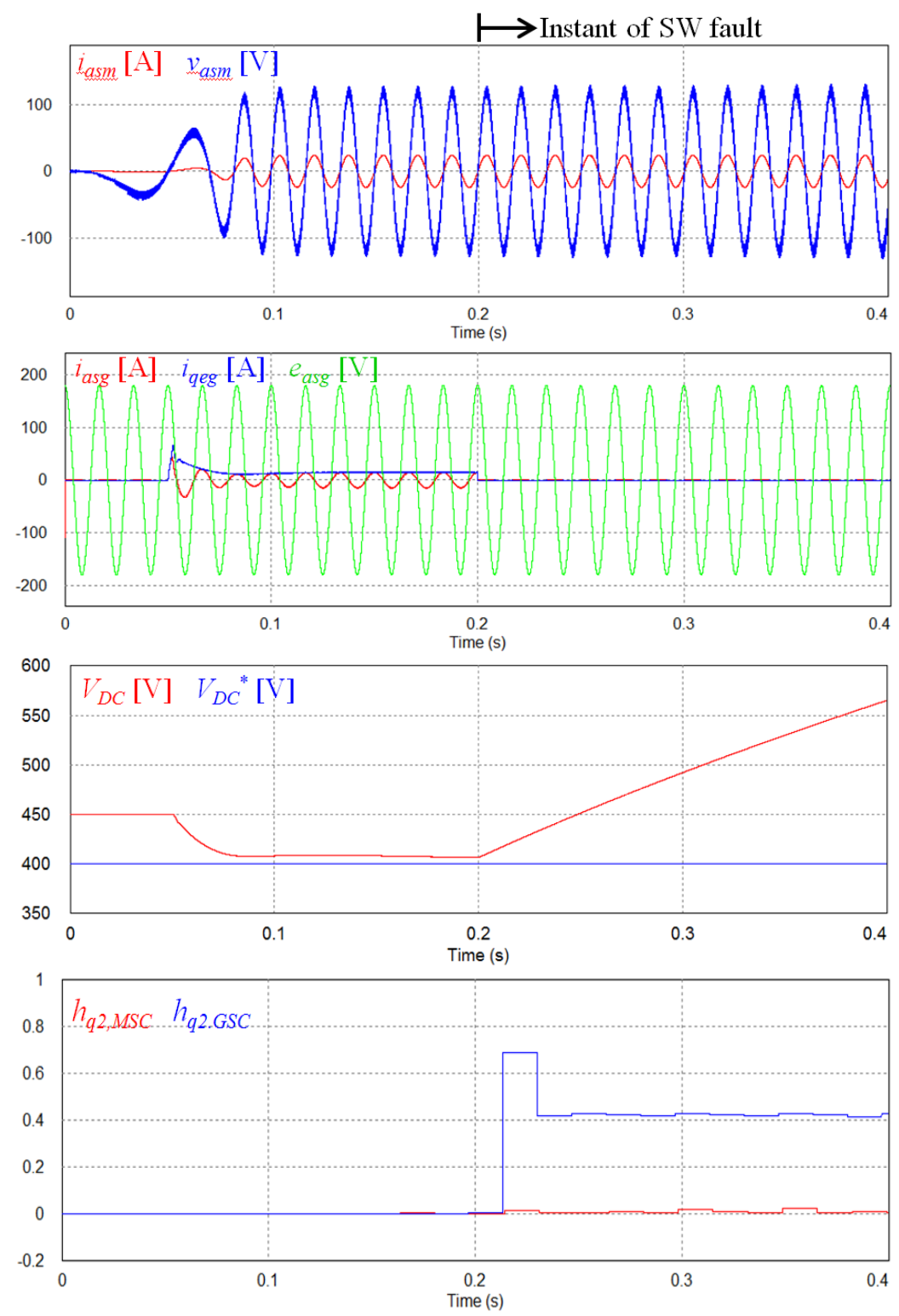

Figure 9. Simulation Results under Entire Switch ( $T_{g a+}$ and $\left.T_{g a-}\right)$ open in the GSC

\section{Conclusions}

In this paper, switch open fault characteristics and simple diagnosis scheme in a PMSG based variable-speed grid-connected wind power conversion has been presented through the integrated simulation study. In the back-to-back converter, the failure in switching devices may occur either in the MSC or in the GSC, which decreases the generator output power and degrades the stability in wind power generation system. If left undetected, this fault may even lead to another failure such as the destruction of DC link capacitor or other electrical components. As an effective diagnostic way, a monitoring scheme for the second-order harmonic components in the $q$-axis current has been proposed, where the harmonic values are simultaneously observed in the MSC as well as in the GSC to monitor abnormal operation of 
system. To determine the harmonic values irrespective of operating conditions, the normalized currents are employed for the harmonic calculation. To verify the effectiveness of the proposed fault diagnosis scheme, the comparative simulation results have been presented. As a result, an on-line simple diagnosis scheme which monitors the condition of generation system can be realized without requiring any additional hardware equipment.

\section{Acknowledgements}

This research was supported by Basic Science Research Program through the National Research Foundation of Korea (NRF) funded by the Ministry of Education (NRF-2014R1A1A2056436).

\section{References}

[1] I. Munteanu, S. Bacha, A. Bratcu, J. Guiraud, and D. Roye, "Energy-reliability optimization of wind energy conversion systems by sliding mode control," IEEE Trans. on Energy Conversion, vol. 23, no. 3, (2008), pp. 975-985.

[2] K. H. Kim, "Performance investigation and observer-based condition monitoring scheme for a PMSG-based grid-connected wind power system under switch open fault," International Journal of Control and Automation, vol. 6, no. 4, (2013), pp. 483-498.

[3] A. D. Hansen and G. Michalke, "Multi-pole permanent magnet synchronous generator wind turbines' grid support capability in uninterrupted operation during grid faults," IET Renewable Power Generation, vol. 3, no. 3, (2009), pp. 333-348.

[4] Z. Chen, J. M. Guerrero, and F. Blaabjerg, "A review of the state of the art of power electronics for wind turbines," IEEE Trans. on Power Electronics, vol. 24, no. 8, (2009), pp. 1859-1875.

[5] P. Caselitz and J. Giebhardt, "Condition monitoring and maintenance strategies for the next generation of large offshore wind turbines," ISET Offshore M\&R Final Public Report.

[6] H. Polinder, H. Lendenmann, R. Chin, and W. M. Arshad, "Fault tolerant generator systems for wind turbines," IEEE International Electric Machines and Drives Conference, (2009), pp. 675-681.

[7] M. A. Parker, Ng Chong, and Ran Li, "Fault-tolerant control for a modular generator converter scheme for direct-drive wind turbines," IEEE Trans. on Industrial Electronics, vol. 58, no. 1, (2011), pp. 305-315.

[8] R. L. A. Ribeiro, C. B. Jacobina, E. R. C. Silva, and A. M. N. Lima, "Fault detection of open-switch damage in voltage-fed PWM motor drive systems," IEEE Trans. Power Electronics, vol. 18, no. 2, (2003), pp. 587593.

[9] B. Lu and S. K. Sharma, "A literature review of IGBT fault diagnostic and protection methods for power inverters," IEEE Trans. on Industry Applications, vol. 45, no. 5, (2009), pp. 1770-1777.

[10] W. S. Im, J. S. Kim, J. M. Kim, D. C. Lee, and K. B. Lee, "Diagnosis methods for IGBT open switch fault applied to three-phase AC/DC PWM converter," Journal of Power Electronics, vol. 12, no. 1, (2012) pp. 120127.

[11] N. M. A. Freire, J. O. Estima, and A.J. M. Cardoso, "A voltage-based approach without extra hardware for open-circuit fault diagnosis in closed-loop PWM AC regenerative drives," IEEE Trans. on Industrial Electronics, vol. 61, no. 9, (2014) pp. 4960-4970.

[12] R. L. A. Ribeiro, C. B. Jacobina, E. R. C. Silva, and A. M. N. Lima, "Fault detection of open-switch damage in voltage-fed PWM motor drive systems," IEEE Trans. on Power Electronics, vol. 18, no. 2, (2003) pp. 587593.

[13] S. Heier and R. Waddington, "Grid integration of wind energy conversion systems," John Wiley \& Sons, (2006).

[14] R. C. Dorf and R. H. Bishop, "Modern control systems,” Prentice-Hall International Editions, (2005).

[15] H. W. van der Broeck, H. C. Skudelny, and G. V. Stanke, "Analysis and realization of a pulsewidth modulator based on voltage space vectors," IEEE Trans. on Industry Applications, vol. 24, no. 1, (1988), pp. $142-150$. 


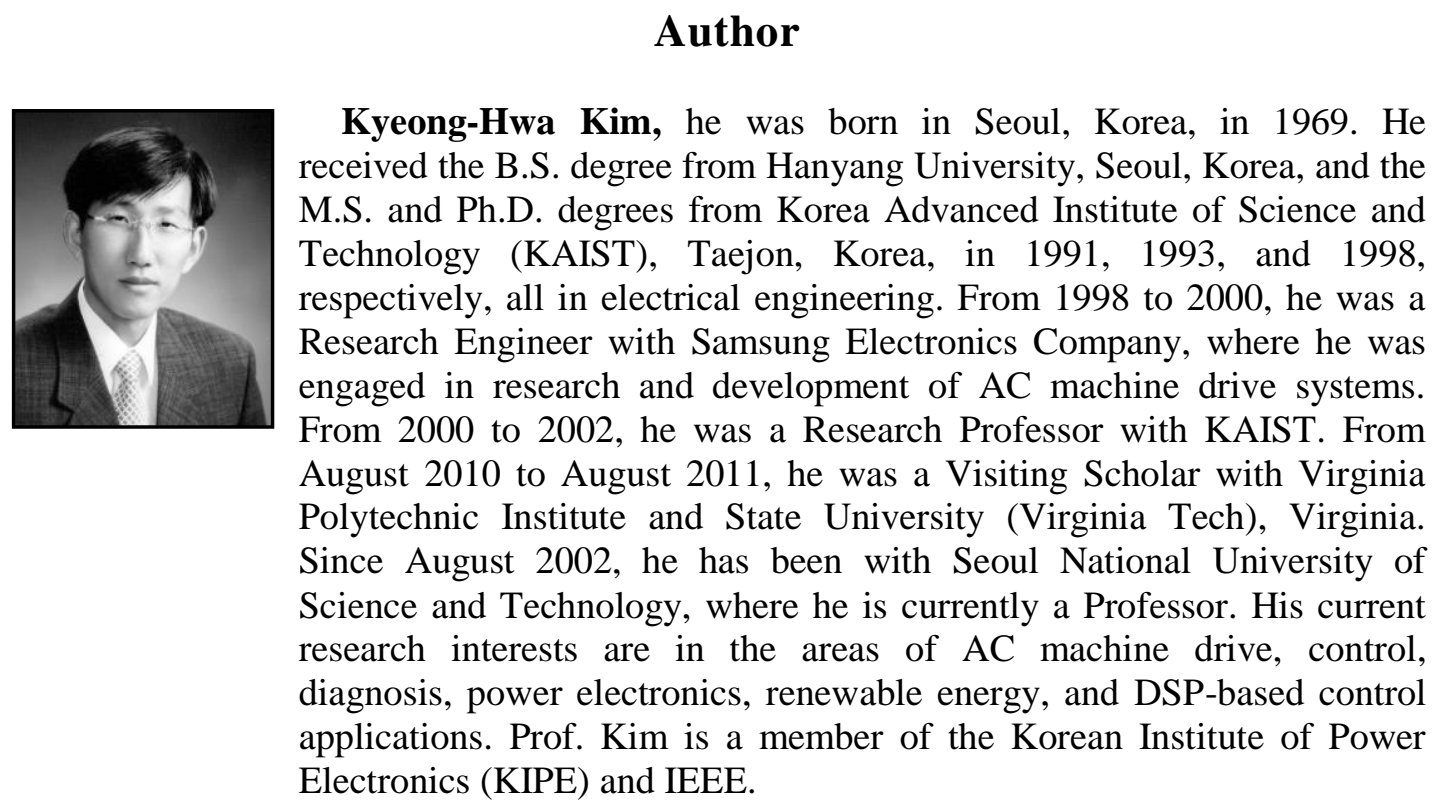


International Journal of Control and Automation Vol.8, No.3 (2015) 